\title{
Development and Characterization of A New Dimethicone Nanoemulsion and its Application for Electronic Gastroscopy Examination
}

This article was published in the following Dove Press journal: International Journal of Nanomedicine

\author{
Suo-Min Feng $\mathbb{D}^{1,2, *}$ \\ Ying Zhao ${ }^{3}$ \\ Qing $X \mathrm{u}^{4}$ \\ Hui-Min $\mathrm{Li}^{5}$ \\ Yu-Xiu Huang ${ }^{6}$ \\ Huan-Huan Liu' \\ Cang-Bao Xu (D) ${ }^{1, *}$
}

'Shaanxi Key Laboratory of Ischemic Cardiovascular Disease, Xi'an Medical University, Xi'an 71002I, People's Republic of China; ${ }^{2}$ School of Pharmacy, Xi'an Medical University, Xi'an 71002I, People's Republic of China; ${ }^{3}$ School of Life Science and Biopharmaceutics, Shenyang Pharmaceutical University, Shenyang II0016, People's Republic of China; ${ }^{4}$ College of Life Sciences, Northwest University, Xi'an 710069, People's Republic of China; ${ }^{5}$ Public Course Teaching Department, Shangluo Vocational and Technical College, Shangzhou, 726000, People's Republic of China; ${ }^{6}$ Department of English, Xi'an Medical University, Xi'an 7I002I,

People's Republic of China

*These authors contributed equally to this work
Correspondence: Suo-Min Feng; CangBao Xu

Xi'an Medical University, No. I, Xinwang

Road, Weiyang District, Xi'an 7I002I,

People's Republic of China

Fax +86 29-86I77539

Email fengsuomin@126.com;

cangboxu@yahoo.com
Purpose: Although the effective and safe medical defoamers, dimethicone (DM) and simethicone (SM) are widely used in electronic gastroscope examination (EGE), their preparations are presented in the form of suspensions or emulsions, these are untransparent or milk-like in appearance and can easily cause misdiagnosis as a result of an unclear field of vision if the doctor does not master the amount of defoamer or operates incorrectly. At the same time, it is also difficult to wash out the camera and pipeline, due to the large oil droplets of preparations. The purpose of this study was to develop a new clear and transparent oil in water $(\mathrm{O} / \mathrm{W}) \mathrm{DM}$ nanoemulsions (DMNs) and observe the effect of application in EGE.

Methods: The oil phase was chosen for its antifoaming activity and viscosity. The emulsifier and co-emulsifier were selected according to the solubility of the oil phase in them. The water titration method was used to make the pseudoternary phase diagrams of nanoemulsions and optimize the prescription composition. DM-in-water nanoemulsion was prepared by the low energy method and evaluated for appearance, antifoaming ability, droplet size, and stability. The effect of DMNs utilized in EGEs was also observed.

Results: The optimal formulation of DMNs contained CRH-40 as an emulsifier, PEG-400 as a co-emulsifier, DM as oil phase with the viscosity of $10 \mathrm{mPa}$.s, and their proportion was 4.5:4.5:1, respectively. DMNs obtained the average particle size of $67.98 \mathrm{~nm}$ with the polydispersity index (PDI) of 0.332 , and $57.14 \%$ defoaming rate. The result of using an EGE showed that DMNs were superior in comparison to the emulsions with regard to the defoaming effect, visual clarity, and easy cleanup.

Conclusion: DMNs were found to provide excellent visual clarity to its other preparations. The novel DMNs is a promising substitute for DM emulsions or suspensions in EGEs.

Keywords: dimethicone, simethicone, dimethicone nanoemulsions, electronic gastroscopy examination, deformer

\section{Introduction}

Electronic gastroscope examination (EGE) is one of the most commonly used methods for diagnosing digestive tract diseases, such as gastritis, gastric ulcer, duodenal ulcer, gastric cancer, ${ }^{1}$ and so on. However, the diagnostic result is easily influenced by the presence of foam, bubbles, mucus, and gas in the stomach, ${ }^{2}$ which often leads to misdiagnosis. So it is necessary during an EGE to apply a defoamer. ${ }^{3,4}$ There are two kinds of defoamer in clinical application. One is the rapid defoamer simethicone $(\mathrm{SM}),{ }^{5-8}$ and the other is the slow defoamer dimethicone (DM), ${ }^{9}$ but they are all dosage forms of suspensions ${ }^{10-13}$ or emulsions to be employed in EGE. ${ }^{14}$ It is well 
known that these two dosage forms are not transparent in appearance, and cannot be diluted with a lot of water. Therefore, they will result in an unclear image if the doctor does not master the amount of defoamer. ${ }^{15}$ Moreover, it is also difficult to quickly clean the camera and pipeline. Nanoemulsions can provide us with a solution for overcoming this problem because of its clear and transparent appearance.

Nanoemulsions, a thermodynamic stable dispersion system with the particle sizes from 10 to $100 \mathrm{~nm}$, are generally composed of emulsifier, co-emulsifier, oil, and water. Small droplet size and uniform size distribution give them a clear and transparent appearance which differs from the milky-white color associated with general emulsions. ${ }^{16-18}$ The droplets of nanoemulsions can be rapidly distributed on the surface of the gastric mucosa without affecting the field of view. Furthermore, there is no oil drops left on the camera, because nanoemulsions can be diluted with more water without demulsification during the cleaning process. According to the composition and properties of $\mathrm{DM}^{19}$ and $\mathrm{SM},{ }^{14}$ only DM can be developed into nanoemulsions.

DM, an oily colorless transparent liquid with a variety of high viscosity, is widely employed in the industrial and cosmetic fields, ${ }^{20}$ but its most important application is as a defoaming agent to eliminate the bubbles in the various sites of the body, for example, the gastro-enteric route. This function makes gastroscopic and enterscopic diagnoses easy in clinic. There are many reports about the preparation of DM emulsions, ${ }^{19,21-24}$ two articles related to the formulation of DM nanoemulsions (DMNs). ${ }^{25,26}$ However, so far, there is no a research about the utilization of clear and transparent DMNs in EGEs.

As an oil phase in prescription, due to high viscosity and strong hydrophobicity of DM, It is not easy to prepare its nanoemulsions. In this work, after using the pseudoternary phase diagram to screen out the composition of the prescription and ratio of the best emulsifier and co-emulsifier, a DM-in-water (oil in water $[\mathrm{O} / \mathrm{W}]$ ) nanoemulsion was prepared using the low energy method. The appearance, particle size, defoaming ability, and stability of the preparation was comprehensively evaluated for the indicators. In addition, the effect of DMNs application in EGEs was also observed. Finally, this study shows that the optimal formulation of DMNs contained polyoxyethylene-40 hydrogenated castor oil (Cremophor RH40) as an emulsifier, polyethylene glycol-400 (PEG-400) as a co-emulsifier, and DM as oil phase with a viscosity of $10 \mathrm{mPa} . \mathrm{s}$, and their proportion was $4.5: 4.5: 1$, respectively. The prepared DMNs achieved the average particle size of $67.98 \mathrm{~nm}$ with the polydispersity index (PDI) of 0.332 , and $57.14 \%$ defoaming rate. The clinical trial results indicated that DMNs was better than DM emulsions in aspect of visual clarity, defoaming effect, and easy cleanup. It can be used as a replacement for DM emulsions or powders in EGEs.

\section{Materials and Methods \\ Materials}

DM with viscosity $10,50,100,350,500,1000 \mathrm{mPa} . \mathrm{s}$ was purchased from USA Dow Corning company. Tween 20, tween 40 , tween 60 , tween 80 , span 80 , and poly (ethylene glycol) 400 (PEG 400) were obtained from Tianjin Kemiou Chemical Reagent Co., Ltd. (Tianjin, China). Polyoxyethylene (40) hydrogenated castor oil (Cremophor RH40, CRH40) was provided by the BASF company (Germany). Glycerol, 1,2-propylene glycol, n-butanol, tert-butanol, ammonium dodecyl sulfate and the other reagents were of analytic grade.

\section{Methods}

\section{Establishment an Evaluation Method for Defoaming Ability}

It is important to set up a method for evaluating the defoaming ability, not only for the choice of the oil phase, but also for the prepared DMNs. The graduated cylinder method was employed and slightly modified. ${ }^{27}$ The operation is as follows: under normal temperature and pressure, a $50 \mathrm{~mL} 1 \%$ dodecyl ammonium sulfate foaming solution was added into a $250 \mathrm{~mL}$ clean graduated cylinder which was then covered with plastic paper and secured with a rubber band. The measuring cylinder was shaken up and down 5 times (up and down is once, amplitude 30-40 cm, speed 50-70 times/min), and the blank foam height $\mathrm{H}_{0}$ was recorded after one minute. In the same manner, $1 \mathrm{~mL}$ testing solution was put into another clean measuring cylinder containing $50 \mathrm{~mL}$ foaming solution, shaken and the foam height $\mathrm{H}$ was recorded. The defoaming rate was calculated using the following equation: defoaming rate $=\left(\bar{H}_{0}-\bar{H}\right) / \bar{H}_{0} \times 100 \% \quad(\mathrm{n}=3)$, where, $\bar{H}_{0}$ represents the average height of the pure foaming liquid (1\% dodecyl ammonium solution) after being shaken in triplicate, $\bar{H}$ is the average foam height after $1 \mathrm{~mL}$ testing solution (defoamer) was added in $50 \mathrm{~mL} 1 \%$ dodecyl ammonium solution and shaken in triplicate. 
DM with different viscosity was taken and diluted separately with tert-butanol to prepare a series of different concentration solutions. Subsequently, the defoaming rate of each concentration was measured, and the defoaming curve (the defoaming rate to concentration) of each viscosity DM was drawn. Finally, the defoaming ability of DM with different viscosities were compared and the optimal defoaming concentration of each viscosity DM was found.

\section{Choice of Oil Phase, Emulsifier and Co- Emulsifier}

The defoaming rates of a series of DM concentrations with different viscosities were determined, moreover, the choice of the oil phase takes into account viscosity and nanoemulsions formation, as well as the defoaming rate.

The emulsifier and co-emulsifier were selected through solubility experiments. ${ }^{28}$ In this test, $1 \mathrm{~mL}$ DM was added to a $10 \mathrm{~mL}$ centrifuge tube, which contained premixed emulsifier/co-emulsifier $(1: 1, \mathrm{v} / \mathrm{v})$. The mixture was sonicated (SB-5200DT, Ningbo, China) in a water bath for 30 min and centrifuged (Allegra 64R Centrifuge, Beckman Coulter) at $9659 \mathrm{~g}$ for $5 \mathrm{~min}$, and then it was observed whether the appearance was clear and layered, according to the DM dissolution behavior, to choose the optimal emulsifier and co-emulsifier.

\section{Prescription Screening of DMNs}

In order to look for the formulation of DMNs, the water titration method was adopted. A mixture of Cremophor RH40/PEG-400 (Km) with the mass ratios of 4:1 to $1: 1$ was added separately to a $100 \mathrm{~mL}$ beaker, stirred at $35^{\circ} \mathrm{C}$, $800 \mathrm{rpm}$ (Constant temperature heating magnetic stirrer, DF-101S, Gongyi, China) for 2 min until the mixture was homogeneous. Subsequently, DM was added to the mixture with a series of mixture/DM ratios from 9:1 to 1:9, respectively. Afterwards, water was dropped into the mixture system until the solution changed from turbid to clear or appeared blue opalescent, this point of change indicated that the DMNs had begun to produce and continued to titrate with water until the DMNs changed from clear to turbidity, which showed the DMN was demulsified, then the titration was stopped and the water volume was recorded at the point of milking and demulsification. The proportion of each component in the entire system was calculated, and the pseudo-ternary phase diagrams of DMNs were drawn using the Origin 7.5 software (Origin Lab Co., Ltd., USA). The nanoemulsion area was calculated with the AUTOCAD2009 software (Autodesk Co., Ltd., USA). The composition of the largest area was the best prescription of the DMNs.

\section{Preparation of DMNs}

The water titration method ${ }^{29,30}$ was used to prepare DMNs. The optimal formulation of DMNs was composed of emulsifier, namely Cremophor RH40, co-emulsifier, namely PEG-400, oil phase, namely DM, and water. The mixture of Cremophor RH40/PEG-400/DM (4.5:4.5:1, w/ $\mathrm{w} / \mathrm{w})$ were stirred thoroughly at $35^{\circ} \mathrm{C}, 800 \mathrm{rpm}$ for $5 \mathrm{~min}$. Water was slowly dropped into the mixture until a nearly homogeneous and transparent solution was formed.

\section{Characterization of DMNs}

The characterization of DMNs includes identification of nanoemulsions types, particle size and distribution, stability and defoaming ability. A water soluble dye of methylene blue was used to identify whether the DMNs is $\mathrm{O} / \mathrm{W}$ type nanoemulsions. The DMNs was diluted 10 times with water, the droplet size distribution and zeta potentials were determined by Malvern Zetasizer ZEN-3600 (Malvern Instruments Ltd., Malvern, UK). DMNs were observed on a Hitachi H-7650 80-kV transmission electron microscope (TEM). The stability research of DMNs was performed on the instrument of Beckman Coulter Allegra 64R Refrigerated Centrifuge (USA). Two duplicates of DMNs were transferred separately into a plastic centrifuge tube, and centrifuged under at room temperature, $3287 \mathrm{~g}$ for $20 \mathrm{~min}$, and $15{ }^{\circ} \mathrm{C}, 15,093 \mathrm{~g}$ for $10 \mathrm{~min}$, respectively. The DMNs amount equivalent to $48 \mathrm{mg} \mathrm{DM}$ was used to determine the defoaming ability according to the method described above.

\section{Observation of Efficacy of DMNs Application in EGE}

The observation of efficacy was carried out in the first affiliated hospital of Xi'an Medical university, and the research protocol was approved by the Medical Ethics Committee of the hospital. The study was conducted in accordance with the Declaration of Helsinki. Moreover, written informed consent was obtained from each patient. Forty outpatients eligible for gastroscopy were randomly divided into two groups, namely the experimental group and the control group. All patients, after recording the basic information, including name, sex, age, symptoms, etc., fasted and were drinking before 
EGE. The patients in the control group received $10 \mathrm{~mL}$ DM emulsions $(10 \mathrm{mg} / \mathrm{mL})$ before $20 \mathrm{~min}$ of the gastroscopy, the drug stayed in the throat for $1 \mathrm{~min}$, and was then swallowed slowly. The patients in the test group employed the DMNs in the same way. The examination was performed using an OLYMPUS GIF-Q260 by one doctor from beginning to end. The defoaming effect, mucosal visibility, washing and sucking times, the degree of ease to clean, adverse reaction and total time for EGEs were compared among the two groups.

To evaluate the clinical effect, it is is necessary to have detailed assessment criteria. The degree of vision clarity and the defoaming effect of the gastroscopy are classified into three levels: excellent, good, and poor . Excellent means that there are no bubbles, and the stomach and mucous membranes are clearly visible; good means that there are a few bubbles and no influence on vision; poor means that there are a large amount of bubbles and paste is attached to the surface of the gastric mucosa, and the visual field is limited. Repeated washing and suction is required. The excellent and good levels are considered effective.

Adverse reactions are indicated by the number of patients who experienced abdominal pain, diarrhoea, nausea and vomiting after taking the preparation. The total examination time refers to the time taken from the beginning of the gastroscopy to enter the esophagus to exiting to the throat.

\section{Statistical Method}

All experimental data were processed by statistical software SPSS 13.0. Measurement data were expressed as mean \pm standard deviation $(\mathrm{X} \pm \mathrm{SD})$, and assessed by t-Student test. The count data analysis were carried out using $\chi^{2}$ test (Chi square test). The difference between groups was considered significant at $\mathrm{P}<0.05$.

\section{Results and Discussion}

The Selecting Results of Emulsifier and

\section{Co-Emulsifier}

Table 1 exhibited the dissolution behavior of DM in different emulsifiers paired with co-emulsifier, only DM in the mixture of Cremophor RH40 and PEG-400 was transparent and no phase separation occurred, so the optimal emulsifier and co-emulsifier were Cremophor RH40 and PEG-400, respectively.
Table I DM Dissolution Situation in Emulsifiers and CoEmulsifiers

\begin{tabular}{|c|c|c|c|c|}
\hline \multirow[t]{2}{*}{ Emulsifier } & \multicolumn{4}{|c|}{ Co-Emulsifier } \\
\hline & Glycerol & $\begin{array}{l}\text { I,2- } \\
\text { Propanediol }\end{array}$ & $\begin{array}{l}\text { n- } \\
\text { Butanol }\end{array}$ & $\begin{array}{l}\text { PEG- } \\
400\end{array}$ \\
\hline Tween 20 & $\mathrm{a}$ & a & a & $\mathrm{a}$ \\
\hline Tween 80 & b & b & b & b \\
\hline Tween 80 & c & c & c & c \\
\hline +span 80 & & & & \\
\hline Cremophor & $d$ & $d$ & $d$ & e \\
\hline $\mathrm{RH} 40$ & & & & \\
\hline
\end{tabular}

Notes: 'Light yellow, demixing, ${ }^{\text {b}}$ Yellow, demixing, ' ${ }^{\text {Dark }}$ yellow, demixing, ${ }^{\mathrm{d}} \mathrm{Clear}$, demixing, ${ }^{e}$ No phase separation, clear.

\section{The Outcome of Oil Phase Screening}

Figure 1 shows the DM defoaming rate rose, but when the DM concentration reached $48 \mathrm{mg} / \mathrm{mL}$ (diluted with tertbutanol), the whole defoaming rate no longer increased. Therefore, $48 \mathrm{mg} / \mathrm{mL}$ DM solution was the optimal concentration of determining defoaming ability, and this amount was also the critical micelle concentration, because DM is a kind of surfactant with a defoaming effect. ${ }^{31}$ Furthermore, DM with different viscosity are all oil and insoluble in water, their hydrophilic-lipophilic balance value (HLB) ${ }^{32-34}$ is between 1 and 3. Figure 1 also shows that the strongest defoaming ability is neither high viscosity (1000 mPa.s) nor low viscosity DM (10 mPa.s and $50 \mathrm{mPa} . \mathrm{s})$, but intermediate viscosity DM (350 mPa.s and $500 \mathrm{mPa} . \mathrm{s})$, this consequence is inconsistent with the literature reports. ${ }^{35,36}$ Many factors may affect the results of measuring the defoaming rate, among them, the method adopted and human operation are the main influencing elements, though the trend of the measurement results is consistent. ${ }^{27,37}$

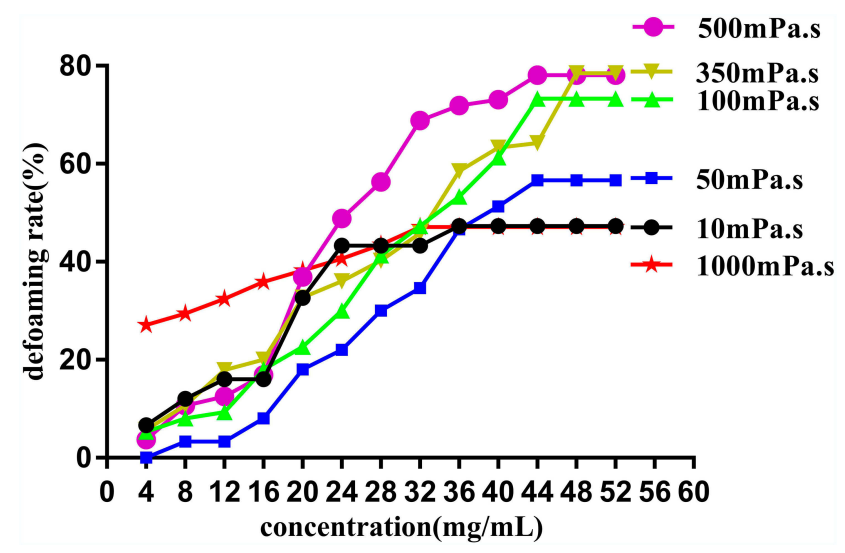

Figure I The defoaming rate curve of different viscosity DM with a series of concentrations. 
Table 2 Nanoemulsion Formation of Different Viscosity DM (Km=4:I to I:I)

\begin{tabular}{|c|c|c|c|c|c|}
\hline \multirow[t]{2}{*}{ Emulsifier and Coemulsifier/DM } & \multicolumn{5}{|c|}{ DM Viscosity (mPa.s) } \\
\hline & 500 & 350 & 100 & 50 & 10 \\
\hline $9: 1$ & a & a & a & a & $\mathrm{a}$ \\
\hline $8: 2$ & a & a & a & $\mathrm{a}$ & $b$ \\
\hline $7: 3$ & a & a & a & a & $b$ \\
\hline $6: 4$ & a & a & a & a & $\mathrm{b}$ \\
\hline $5: 5,4: 6 \sim 1: 9$ & c & c & c & c & c \\
\hline
\end{tabular}

Notes: ${ }^{\mathrm{a}}$ Transparent nanoemulsion formation, demixing after $24 \mathrm{~h},{ }^{\mathrm{b}}$ Transparent nanoemulsion formation, no phase separation after $24 \mathrm{~h}$, ${ }^{\mathrm{c}}$ No nanoemulsion formation.

In order to choose a suitable oil phase, besides the viscosity and defoaming rate of $\mathrm{DM}$, it is essential to consider the emulsification situation of DM with different viscosity in the mixture of emulsifier, co-emulsifier and water. Table 2 indicates different $\mathrm{K}_{\mathrm{m}}$ (emulsifier/co-emulsifier, 4:1, 3:1, 2:1, 1:1), the mixture (emulsifier and coemulsifier), and DM in weight ratios from 9:1 to 1:9. Water titration was used to form nanoemulsion status. It was obvious that only DM with the viscosity $10 \mathrm{mPa}$.s could produce a transparent nanoemulsion and no phase separation had occurred after $24 \mathrm{~h}$. Hence, DM with the viscosity $10 \mathrm{mPa}$.s was the best choice for the oil phase. This outcome conformed to the oil phase selection principle of nanoemulsions, in other words, the oil phase is preferably pure in composition and small in molecular weight. $^{29,38}$

\section{Optimal Formulation of DMNs}

$\mathrm{K}_{\mathrm{m}}$ value is the ratio of emulsifier to co-emulsifier. Tables 3-7 showed emulsifying condition of $K_{m}$ from 4:1 to $1: 2$, and mixed emulsifier (emulsifier and co-emulsifier)/DM from 9:1 to 1:9. Among them, except $\mathrm{K}_{\mathrm{m}}=1: 2$ and other $\mathrm{Km}$ of mixed emulsifier/DM after 5:5, the left can form nanoemulsions when prepared with a mixed emulsifier/DM from 9:1 to 6:4. A pseudo-ternary phase diagram (Figure 2A-D) was constructed to identify the nanoemulsifying region and to optimize the concentration of DM, Cremophor RH40 and PEG-400. According to the

Table $3 \mathrm{Km}=4: \mathrm{I}$, The Emulsifying Phenomenon of Mixed Emulsifier and Oil Phase in Different Proportion

\begin{tabular}{|l|l|l|l|l|l|l|}
\hline $\begin{array}{l}\text { Mixed } \\
\text { Emulsifier /DM }\end{array}$ & $\begin{array}{l}\text { CRH-40 g } \\
\text { (\%) }\end{array}$ & $\begin{array}{l}\text { PEG-400 g } \\
\text { (\%) }\end{array}$ & DM g (\%) & $\begin{array}{l}\text { Water, g (\%) (Turbid to } \\
\text { Clear) }\end{array}$ & $\begin{array}{l}\text { Water, g (\%) (Clear to } \\
\text { Turbid) }\end{array}$ & $\begin{array}{l}\text { Appearance } \\
9: 1\end{array}$ \\
$8: 2$ & $4.0(34.6,29.5)$ & $1.0(8.7,7.4)$ & $0.56(4.8,4.1)$ & $6.0(51.9)$ & $8.0(59.0)$ & $\mathrm{a}$ \\
$7: 3$ & $4.0(33.8,28.1)$ & $1.0(8.4,7.0)$ & $1.25(10.5,8.8)$ & $5.6(47.3)$ & $8.0(56.1)$ & $\mathrm{a}$ \\
$6: 4$ & $4.0(29.1,27.9)$ & $1.0(7.3,7.0)$ & $2.14(15.6,14.9)$ & $6.6(48.0)$ & $7.2(50.2)$ & $\mathrm{b}$ \\
$5: 5$ & $4.0(27.1,26.1)$ & $1.0(6.8,6.5)$ & $3.33(22.6,21.7)$ & $6.4(43.5)$ & $7.0(45.3)$ & $\mathrm{b}$ \\
$4: 6 \sim 1: 9$ & 4.0 & 1.0 & 5.0 & & & $\mathrm{c}$ \\
\hline
\end{tabular}

Notes: ${ }^{\mathrm{a}}$ Transparent nanoemulsion formation, no phase separation after $24 \mathrm{~h},{ }^{\mathrm{b}}$ Transparent nanoemulsion formation, demixing after $24 \mathrm{~h},{ }^{\mathrm{C}}$ No nanoemulsion formation.

Table $4 \mathrm{Km}=3: \mathrm{I}$, The Emulsifying Phenomenon of Mixed Emulsifier and Oil Phase in Different Proportion

\begin{tabular}{|l|l|l|l|l|l|l|}
\hline $\begin{array}{l}\text { Mixed } \\
\text { Emulsifier/DM }\end{array}$ & $\begin{array}{l}\text { CRH-40 g } \\
\text { (\%) }\end{array}$ & $\begin{array}{l}\text { PEG-400 g } \\
\text { (\%) }\end{array}$ & DM g (\%) & $\begin{array}{l}\text { Water, g (\%) (Turbid to } \\
\text { Clear) }\end{array}$ & $\begin{array}{l}\text { Water, g (\%) (Clear to } \\
\text { Turbid) }\end{array}$ & $\begin{array}{l}\text { Appearance } \\
\text { 9:1 }\end{array}$ \\
$8: 2$ & $3.0(29.9,26.7)$ & $1.0(10.0,8.9)$ & $0.45(4.5,4.0)$ & $5.6(55.7)$ & $6.8(60.4)$ & $\mathrm{a}$ \\
$7: 3$ & $3.0(30.0,27.3)$ & $1.0(10.0,9.1)$ & $1.0(10.0,9.1)$ & $5.0(50.0)$ & $6.0(54.5)$ & $\mathrm{a}$ \\
$6: 4$ & $3.0(28.0,25.6)$ & $1.0((9.3,8.6)$ & $1.7(16.0,14.6)$ & $5.0(46.7)$ & $6.0(51.2)$ & $\mathrm{b}$ \\
$5: 5$ & $3.0(24.4,23.7)$ & $1.0(8.2,7.9)$ & $2.67(21.8,21.1)$ & $5.6(45.6)$ & $6.0(47.3)$ & $\mathrm{b}$ \\
$4: 6 \sim 1: 9$ & 3.0 & 1.0 & 4.0 & & & $\mathrm{c}$ \\
\hline
\end{tabular}

Notes: ${ }^{a}$ Transparent nanoemulsion formation, no phase separation after $24 \mathrm{~h},{ }^{\mathrm{b}}$ Transparent nanoemulsion formation, demixing after $24 \mathrm{~h}$, ${ }^{\mathrm{c}} \mathrm{No}$ nanoemulsion formation. 
Table $5 \mathrm{Km}=2: \mathrm{I}$, The Emulsifying Phenomenon of Mixed Emulsifier and Oil Phase in Different Proportion

\begin{tabular}{|l|l|l|l|l|l|l|}
\hline $\begin{array}{l}\text { Mixed } \\
\text { Emulsifier/DM }\end{array}$ & $\begin{array}{l}\text { CRH-40 g } \\
\text { (\%) }\end{array}$ & $\begin{array}{l}\text { PEG-400 g } \\
\text { (\%) }\end{array}$ & DM g (\%) & $\begin{array}{l}\text { Water, g (\%) (Turbid to } \\
\text { Clear) }\end{array}$ & $\begin{array}{l}\text { Water, G (\%) (Clear to } \\
\text { Turbid) }\end{array}$ & Appearance \\
\hline $9: 1$ & $4.0(34.3,30.1)$ & $2.0(17.2,15.1)$ & $0.67(5.7,5.0)$ & $5.0(42.8)$ & $6.6(49.7)$ & a \\
$8: 2$ & $4.0(32.0,29.6)$ & $2.0(16.0,14.8)$ & $1.5(12.0,11.1)$ & $5.0(40.0)$ & $6.0(44.5)$ & $\mathrm{a}$ \\
$7: 3$ & $4.0(25.7,24.1)$ & $2.0(12.8,12.1)$ & $2.57(16.5,15.5)$ & $7.0(45.0)$ & $8.2(48.3)$ & $\mathrm{b}$ \\
$6: 4$ & $4.0(23.5,22.2)$ & $2.0(11.8,11.1)$ & $4.0(23.5,22.2)$ & $7.0(41.2)$ & $8.0(44.4)$ & $\mathrm{b}$ \\
$5: 5$ & 4.0 & 2.0 & 6.0 & & & $\mathrm{c}$ \\
$4: 6 \sim 1: 9$ & 4.0 & 2.0 & & & & $\mathrm{c}$ \\
\hline
\end{tabular}

Notes: ${ }^{\mathrm{a}}$ Transparent nanoemulsion formation, no phase separation after $24 \mathrm{~h},{ }^{\mathrm{b}}$ Transparent nanoemulsion formation, demixing after 24 h, ${ }^{\mathrm{c}}$ No nanoemulsion formation.

Table $6 \mathrm{Km}=\mathrm{I}: \mathrm{I}$, The Emulsifying Phenomenon of Mixed Emulsifier and Oil Phase in Different Proportion

\begin{tabular}{|l|l|l|l|l|l|l|}
\hline $\begin{array}{l}\text { Mixed } \\
\text { Emulsifier /DM }\end{array}$ & $\begin{array}{l}\text { CRH-40 g } \\
\text { (\%) }\end{array}$ & $\begin{array}{l}\text { PEG-400 g } \\
\text { (\%) }\end{array}$ & DM g (\%) & $\begin{array}{l}\text { Water, g (\%) (Turbid to } \\
\text { Clear) }\end{array}$ & $\begin{array}{l}\text { Water, g (\%) (Clear to } \\
\text { Turbid) }\end{array}$ & Appearance \\
\hline $9: 1$ & $4.0(22.4,18.4)$ & $4.0(22.4,18.4)$ & $0.89(5.0,4.1)$ & $9.0(50.3)$ & $12.8(59.0)$ & $12.0(54.5)$ \\
$8: 2$ & $4.0(20.6,18.2)$ & $4.0(20.6,18.2)$ & $2.0(10.3,9.1)$ & $9.4(48.5)$ & $12.2(51.7)$ & $\mathrm{a}$ \\
$7: 3$ & $4.0(19.6,16.9)$ & $4.0(19.6,16.9)$ & $3.4(16.7,14.4)$ & $9.0(44.1)$ & $12.0(47.4)$ & $\mathrm{a}$ \\
$6: 4$ & $4.0(17.2,15.8)$ & $4.0(17.2,15.8)$ & $5.3(22.7,20.9)$ & $10.0(42.9)$ & $\mathrm{a}$ \\
$5: 5$ & 4.0 & 4.0 & 8.0 & & $\mathrm{c}$ \\
$4: 6 \sim 1: 9$ & 4.0 & 4.0 & & & & $\mathrm{c}$ \\
\hline
\end{tabular}

Notes: ${ }^{\mathrm{a}}$ Transparent nanoemulsion formation, no phase separation after $24 \mathrm{~h},{ }^{\mathrm{b}}$ Transparent nanoemulsion formation, demixing after 24 h, ${ }^{\mathrm{C}}$ No nanoemulsion formation.

Table $7 \mathrm{Km}=1: 2$ the Emulsifying Phenomenon of Mixed Emulsifier and Oil Phase in Different Proportion

\begin{tabular}{|l|l|l|l|l|l|l|}
\hline $\begin{array}{l}\text { Mixed Emulsifier } \\
\text { IDM }\end{array}$ & $\begin{array}{l}\text { CRH-40 g } \\
\text { (\%) }\end{array}$ & $\begin{array}{l}\text { PEG-400 g } \\
\text { (\%) }\end{array}$ & $\begin{array}{l}\text { DM g } \\
\text { (\%) }\end{array}$ & $\begin{array}{l}\text { Water, g (\%) (Turbid to } \\
\text { Clear) }\end{array}$ & $\begin{array}{l}\text { Water, g (\%) (Clear to } \\
\text { Turbid) }\end{array}$ & \begin{tabular}{l} 
Appearance \\
\hline $9: 1$
\end{tabular} \\
$8: 2$ & 1.0 & 2.0 & 0.33 & 2.6 & & $\mathrm{c}$ \\
$7: 3$ & 1.0 & 2.0 & 0.75 & 2.8 & $\mathrm{c}$ \\
$6: 4$ & 1.0 & 2.0 & 1.3 & & $\mathrm{c}$ \\
$5: 5$ & 1.0 & 2.0 & 2.0 & & $\mathrm{c}$ & $\mathrm{c}$ \\
$4: 6 \sim 1: 9$ & 1.0 & 2.0 & 3.0 & & $\mathrm{c}$ \\
\hline
\end{tabular}

Notes: ${ }^{a}$ Transparent nanoemulsion formation, no phase separation after 24 h, ${ }^{\mathrm{b}}$ Transparent nanoemulsion formation, demixing after $24 \mathrm{~h}$, ${ }^{\mathrm{C}}$ No nanoemulsion formation.

results of calculation by the AUTOCAD2009 software, the nanoemulsion areas in the pseudo-ternary phase diagram were 8785.13 un (Figure 2D, $\mathrm{K}_{\mathrm{m}}=1: 1$ ), 6523.66 un (Figure $2 \mathrm{~A}, \mathrm{~K}_{\mathrm{m}}=4: 1$ ), 5962.51 un (Figure $2 \mathrm{C}, \mathrm{K}_{\mathrm{m}}=2: 1$ ), and 5030.85 un (Figure $2 B, K_{m}=3: 1$ ). It was obvious that Figure $2 \mathrm{D}$ of $\mathrm{K}_{\mathrm{m}}=1: 1$ displayed the maximum nanoemulsion area, and there were four formulations under $\mathrm{K}_{\mathrm{m}}=1: 1$, namely, the mixed emulsifier/DM from 9:1 to 6:4. These ratio nanoemulsions were prepared, and the particle sizes as well as zeta-potentials were determined as presented in Table 8. The results showed that the composition of mixed emulsifier/DM (9:1) in $K_{m}$ (1:1) gained the smallest PDI and zeta-potential as well as almost similar particle size. The PDI value and zeta-potential was low and confirmed that the nanoemulsion was relatively stable, and had a narrow size distribution, with no phase separation.
Therefore, the optimal prescription of DMNs was constituted of water and Cremophor RH40/PEG-400/DM with the ratio of 4.5:4.5:1 (w/w/w), respectively.

Nanoemulsions region should be in the range from milking to demulsification, that is, from the beginning of the water titration to form an emulsion to the end of continuous water addition. The titration phenomenon presented started turbid to clear, and ended clear to turbid. ${ }^{25}$ However, a few research papers showed a point, not a region in the procedure of their pseudo-ternary phase diagrams construction, ${ }^{26,39-42}$ this question needs to be deliberated.

\section{The Characterization of DMNs}

Figure 3 exhibited the picture taken under optical microscope, DMNs dyed with methylene blue and the droplet was colored blue on the outside. This appearance indicated 

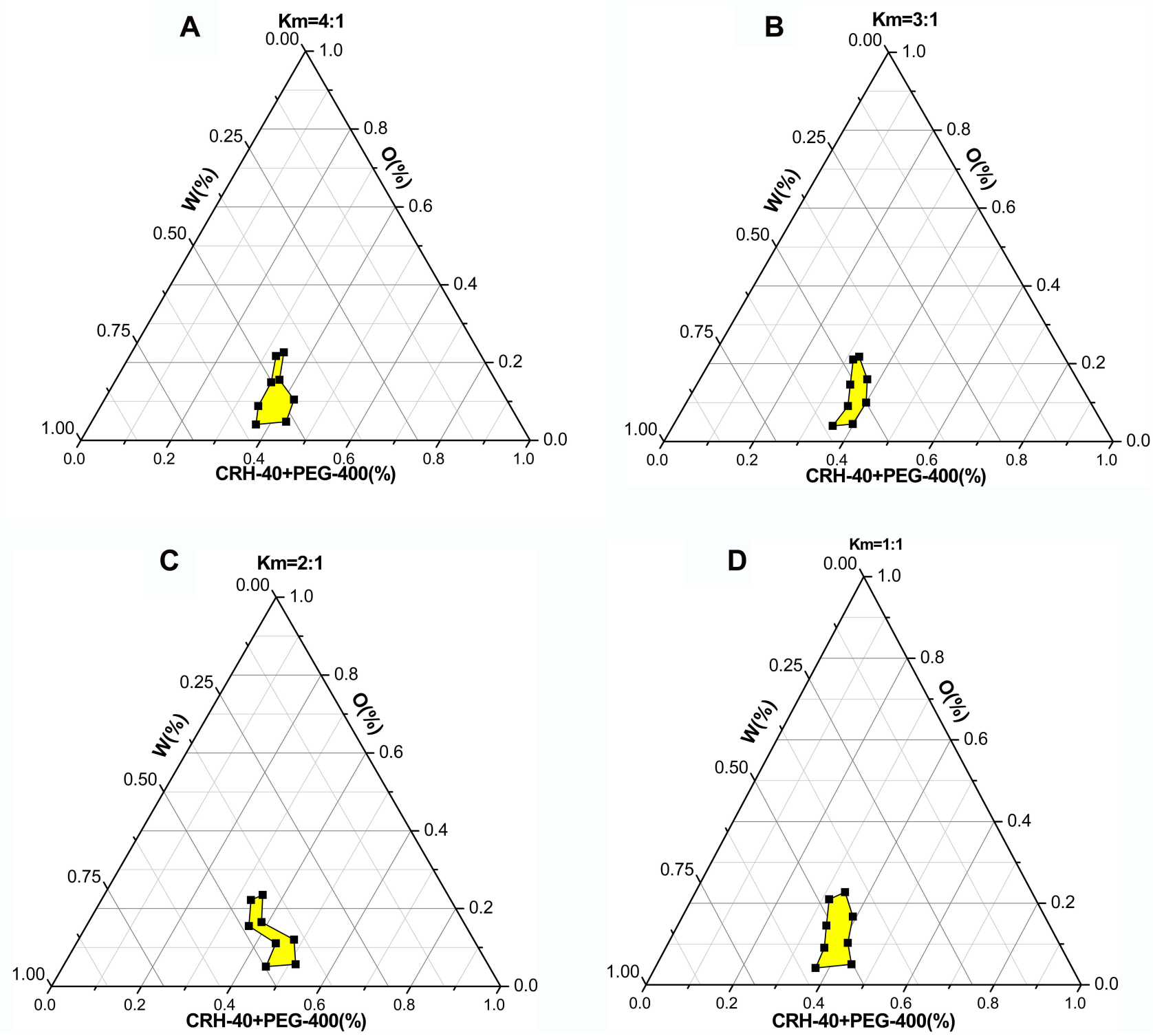

Figure 2 Pseudo-ternary phase diagram with different $\mathrm{Km}$.

Notes: (A) Cremophor RH40/PEG-400 (Km) with the mass ratios of 4:I, (B) Km=3:I, (C) $\mathrm{Km}=2: 1$, (D) $\mathrm{Km}=\mathrm{I:I}$

that DMNs was a type of $\mathrm{O} / \mathrm{W}$ nanoemulsions, because methylene blue is a water-soluble dye. ${ }^{26}$ The droplets size and size distribution of prepared DMNs was as illustrated in Figure 4 in which the particle size distribution was only one peak, the mean droplet size of DMNs was found in $67.98 \mathrm{~nm}$. Figure 5 shows that the zeta potential distribution of DMNs was about $-1.81 \mathrm{mv}$. At different magnifications, the transmission electron microscopy (TEM) images of the prepared DMNs (Figure 6A-C) revealed that the droplets were spherical in shape, transparent inside and of uniform size, less than $70 \mathrm{~nm}$. Centrifugation was employed in the research on the stability of DMNs. The results indicated that DMNs was homogeneous and transparent in shape, no physical changes and no phase separation occurred under the centrifugation of room and low temperature. The defoaming rate of DMNs reached $57.41 \%$ on the basis of an equal amount of DM, and the defoaming ability was superior in comparison to its emulsions or suspensions of DM in vitro.

\section{Utilizing Effects of EGE}

In Table 9 it can be seen that there is no significant difference in the defoaming effect and the clarity of the 
Table $8 K_{m}=I: I$, The Particle Size, PDI and Zeta-Potential of DMNs in Different Proportion of Mixed Emulsifier/DM

\begin{tabular}{|c|l|l|l|l|}
\hline $\mathbf{K}_{\mathbf{m}}$ & $\begin{array}{l}\text { Mixed } \\
\text { Emulsifierl } \\
\text { DM }\end{array}$ & $\begin{array}{l}\text { The Average } \\
\text { Particle Size (nm) }\end{array}$ & $\begin{array}{l}\text { Zeta- } \\
\text { Potential } \\
(\mathbf{m v})\end{array}$ & PDI \\
\hline I:I & $9: 1$ & 67.98 & -1.81 & 0.266 \\
& $8: 2$ & 62.95 & -0.328 & 0.476 \\
& $7: 3$ & 65.47 & -0.168 & 0.511 \\
& $6: 4$ & 63.58 & -0.139 & 0.55 \\
\hline
\end{tabular}

gastroscopy field of vision between the excellent and good levels of the two groups. However, in the poor level, a significant statistical difference has emerged $(p<0.01)$, the control group is lower than the test group in visual clarity, as is presented in Figure 7A in which gastroscopy images, the stomach, and the gastric mucosal surface were partially covered by the paste coming from DM preparations. This

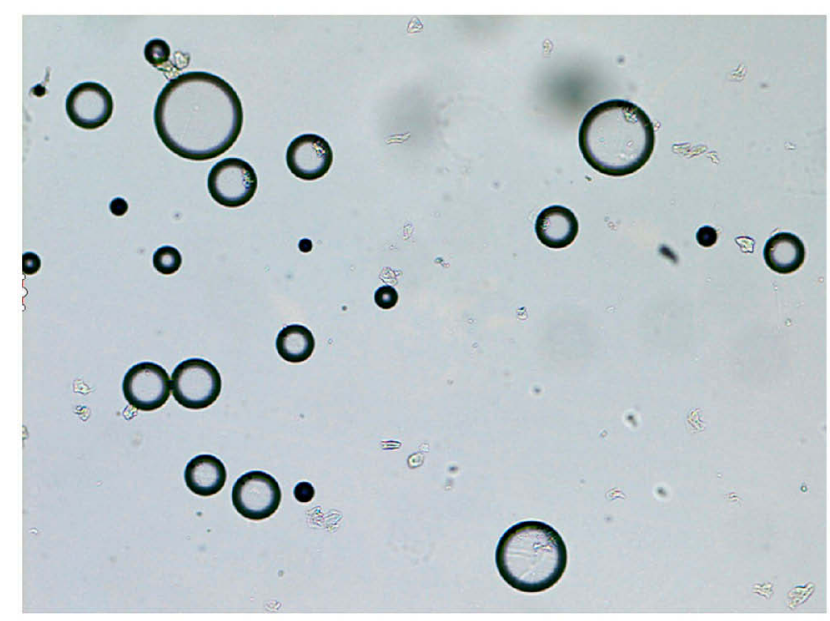

Figure 3 Picture under microscope of DMNs dyeing with methylene blue.

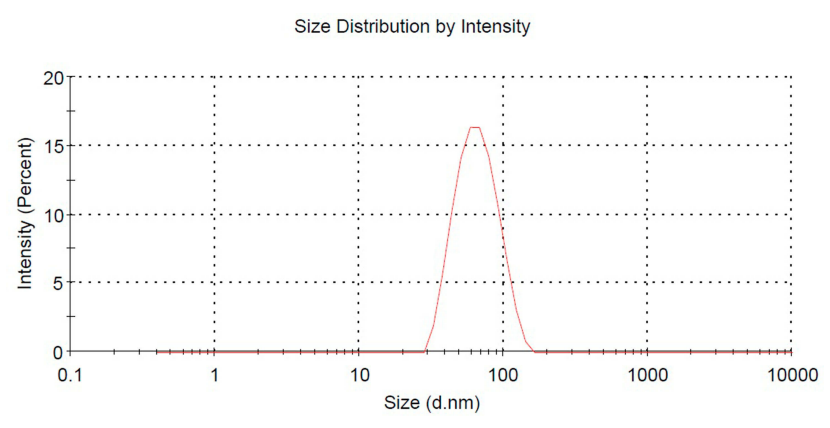

Figure 4 The particle size distribution curve of DMNs.

situation is consistent with prior studies. ${ }^{13}$ The severe obscuration affects vision and diagnosis, only resolved by repeated washing and suction, but in the experimental group of utilizing DMNs (Figure 7B), this obscuration rarely happens. This is because most defoaming agents are all oil, insoluble in water, and only used in the forms of suspensions or emulsions in a clinic, while DMNs is a clear and transparent $\mathrm{O} / \mathrm{W}$ defoaming formulation. Figure 7C showed that mucus and foam often affected a gastroscopy's visual field and diagnosis without the defoaming preparation.

The total examination time in control group and test group are $11 \pm 1.3 \mathrm{~min}$ and $10 \pm 2.2 \mathrm{~min}$, respectively. Obviously this is not a statistically significant difference ( $\mathrm{P} \geq 0.05$ ), but the mean time in the control group seems to be longer. This is associated with the DM emulsions or suspensions which partially adhere to the surface of the gastric mucosa, obstructing visibility, and requiring frequent washing and suction.

As shown in Table 10, there is no obvious difference in adverse reactions between the two groups and no

Zeta Potential Distribution

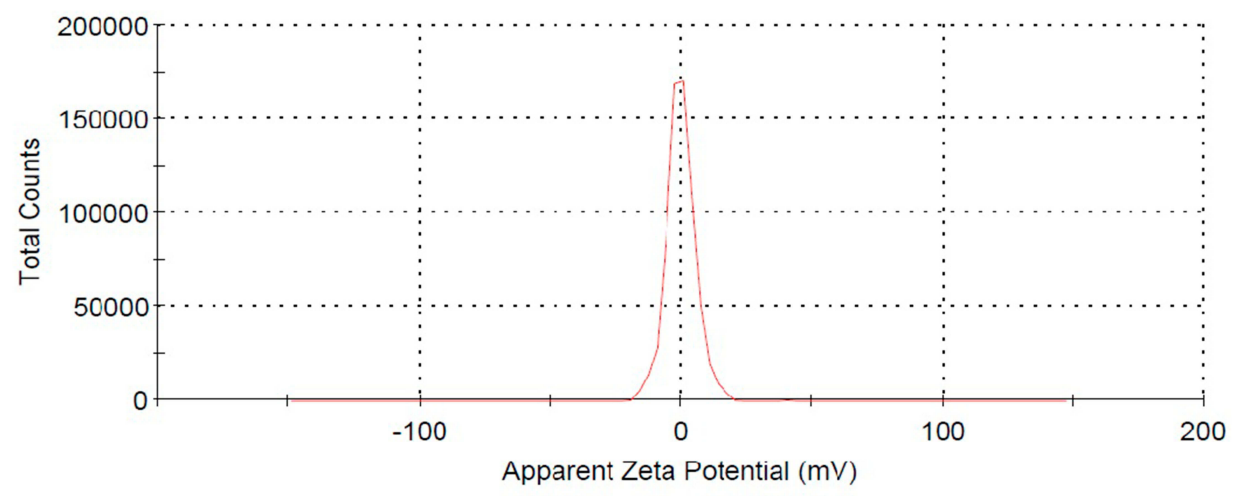

Figure $\mathbf{5}$ The zeta potential distribution of DMNs. 

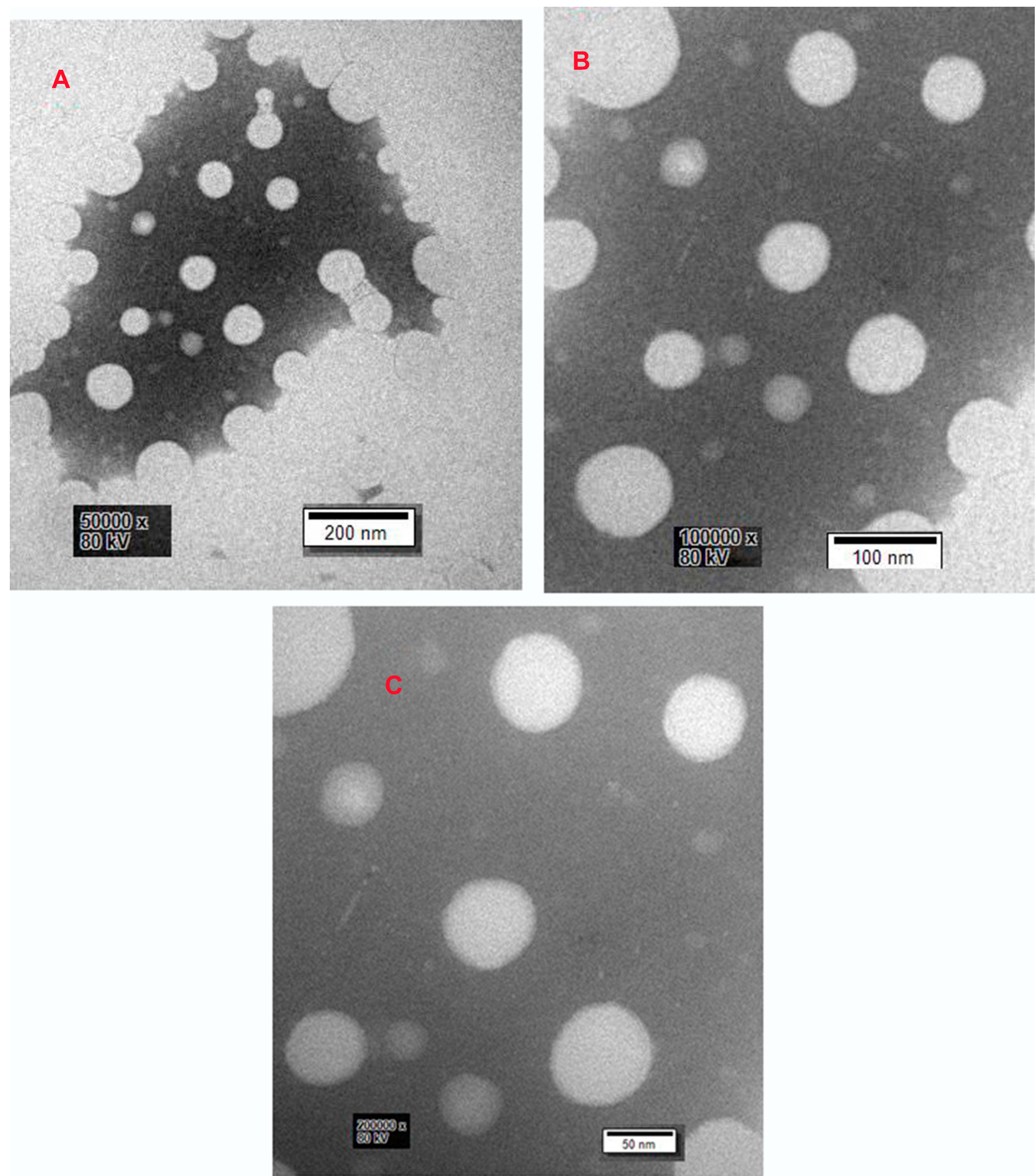

Figure 6 The transmission electron microscopy images (TEM) of the prepared DMNs showing the shape and size. Notes: (A) 50,000 multiples, (B) 100,000 multiples, and (C) 200,000 multiples. Which showed spherical shape, size $50 \mathrm{~nm}$.

serious adverse reaction occurred in either group, with a few members mainly presenting with such gastrointestinal symptoms as abdominal pain, nausea, vomiting, and mild discomfort. The appearance of these symptoms is related either to the DM preparations or operational irritation. This result reveals that the DM preparations are relatively safe and tolerant to patients. In addition, there is a bitter and astringent taste in two groups' 
Table 9 The Defoaming Effect and Vision Clarity in Two Groups

\begin{tabular}{|l|l|l|l|l|}
\hline Level & $\begin{array}{l}\text { Test Group } \\
(\mathbf{n = 2 0 )}\end{array}$ & $\begin{array}{l}\text { Control Group } \\
(\mathbf{n = 2 0 )}\end{array}$ & $\chi^{2}$ & $\mathbf{P}$ \\
\hline $\begin{array}{l}\text { Excellent } \\
(\mathrm{n}, \%)\end{array}$ & $10(50.0)$ & $8(40.0)$ & 22.86 & $<0.01$ \\
$\begin{array}{l}\text { Good (n,\%) } \\
\text { Poor }(\mathrm{n}, \%)\end{array}$ & $\begin{array}{l}8(40.0) \\
2(10.0)\end{array}$ & $\begin{array}{l}7(35.0) \\
5(25.0)\end{array}$ & & \\
\hline
\end{tabular}

Table 10 The Adverse Reaction in Two Groups (n, \%)

\begin{tabular}{|l|l|l|l|l|}
\hline $\begin{array}{l}\text { Adverse } \\
\text { Reaction }\end{array}$ & $\begin{array}{l}\text { Test Group } \\
(\mathbf{n}=\mathbf{2 0 )}\end{array}$ & $\begin{array}{l}\text { Control Group } \\
(\mathbf{n}=\mathbf{2 0 )}\end{array}$ & $\chi^{\mathbf{2}}$ & $\mathbf{P}$ \\
\hline $\begin{array}{l}\text { Abdominal pain } \\
(\mathrm{n}, \%)\end{array}$ & $2(10.0)$ & $\mathrm{I}(5.0)$ & 0 & $\geq 0.05$ \\
Diarrhoea (n,\%) & $0(0.0)$ & $0(0.0)$ & & \\
Nausea (n,\%) & $5(25.0)$ & $6(30.0)$ & & \\
Vomiting (n,\%) & $0(0.0)$ & $\mathrm{I}(5.0)$ & & \\
Total (n) & $7(35.0)$ & $8(40.0)$ & & \\
\hline
\end{tabular}

preparations. Thus, the flavor needs to be improved in future developments.

To our knowledge, this is the first study to employ DMNs in EGEs and assess its effectiveness with DM in other preparations. Clinical trial results indicate that the DMNs can improve the visibility of the gastroscopy field of vision and can reduce deposition of the preparation in the stomach and the gastric mucosa surface. This advantage of improving image quality may be helpful for increasing the detection rate of early gastrointestinal diseases. Therefore, DMNs is worthy of applying in EGEs.

There are a few limitations in our study. First, in the formulation of DMNs, there exists a large amount of emulsifier and co-emulsifiers. This disadvantage is a common problem of nanoemulsions. ${ }^{18,43,44}$ Second, the acute toxicity test of DMNs in mice shows no toxicity and the use of DMNs in EGE only happened once. Moreover, DM, PEG-400 and CRH-400 in the prescription used have been approved by the FDA. So it is theoretically speculated that the DMNs should be relatively safe and non-toxic. But the body processes, absorption sites, ${ }^{42,45}$ as well as long-term toxicity of DMNs, have not been performed. Third, during the gastroscopy to observe the effect of the drug, administered via the tube injection method ${ }^{13}$ (the insertion of a plastic tube through a gastroscopy biopsy hole) is a reliable scheme to evaluate the effect of drug, which can be used to show the contrast before and after administration. In other words, if bubbles and mucus are found in the stomach (Figure 7C),
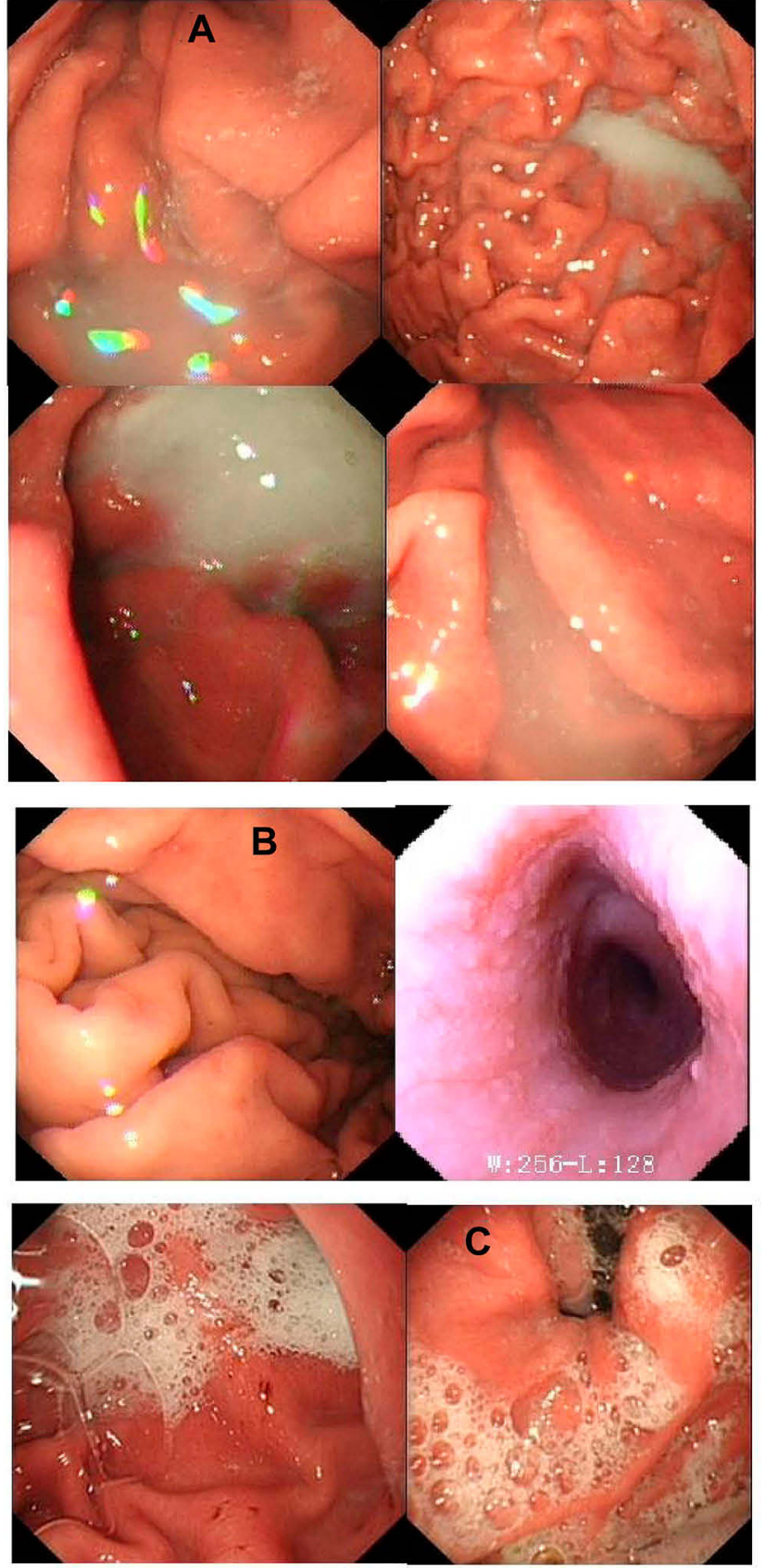

Figure 7 The electronic gastroscope images collected under different conditions. Notes: (A) Poor level gastroscopy images from the control groups: severe obscuration of the gastric mucosa surface caused by paste coming from DM preparations, (B) The clear images from the test group with the DMNs, and (C) Gastroscopy images taken without antifoam: mucus and foam affect vision.

then the preparation is administered by the tube injection method. This method is not only cumbersome and timeconsuming, but also does not meet ethical requirements. In contrast, oral administration is a convenient and routine way to evaluate the defoaming preparations, but the outcome is a statistical probability. Finally, due to the small sample enrolled in clinical trials, the results are only a trend, and 
the efficacy of DMNs needs to be confirmed by a large randomized clinical test. Therefore, there will be a lot of basic work to be done before its clinical application.

\section{Conclusion}

In this study, a novel and transparent $\mathrm{O} / \mathrm{W}$ DMNs was prepared and characterized. The optimal formulation of DMNs was composed of CRH-40 as emulsifier, PEG-400 as co-emulsifier, DM as oil phase with viscosity of 10 $\mathrm{mPa} . \mathrm{s}$, and their proportion was 4.5:4.5:1, respectively. The result of using this in an EGE showed that DMNs was superior in comparison to its emulsions in improving image quality and reducing misdiagnosis, due to the high defoaming effect, visual clarity, and easy cleanup. Therefore, DMNs is only one transparent defoamer formulation available for EGE, and is recommended as one of the promising substitutes for DM emulsions or powders in EGEs.

\section{Acknowledgments}

The authors would like to acknowledge the financial support from the Open fund of Shaanxi Key Laboratory of Ischemic Cardiovascular Disease (No. 2017ZDKF03), Project of Shangluo Vocational and Technical College in 2019 (JXKT2019002) and Provincial Key Discipline Construction Project of Xi'an Medical UniversityPharmacy (No. 2016YXXK12).

\section{Disclosure}

The authors report no conflicts of interest in this work.

\section{References}

1. Kim GH, Cho YK, Cha JM, Lee SY, Chung IK. Efforts to increase image quality during endoscopy: the role of pronase. World $J$ Gastrointest Endosc. 2016;8:267-272. doi:10.4253/wjge.v8.i5.267

2. Kwan V, Deviere J. Endoscopy essentials: preparation, sedation, and surveillance. Endoscopy. 2008;40(1):65-70. doi:10.1055/s-2007-967 046

3. Gasster M, Westwater JO, Molle WE. Use of defoaming agent in gastroscopy. Gastroenterology. 1954;27:652-655. doi:10.1016/S00165085(19)36108-6

4. Enns R. Capsule endoscopy: in search of the ideal image. Am J Gastroenterol. 2008;103(1):83-85. doi:10.1111/j.1572-0241.2007.01 629.x

5. Brecevic L, Bosan-Kilibarda I, Strajnar F. Mechanism of antifoaming action of simethicone. J Appl Toxicol. 1994;14:207-211. doi:10.1002/ jat.2550140311

6. Matro R, Tupchong K, Daskalakis C, Gordon V, Katz L, Kastenberg D. The effect on colon visualization during colonoscopy of the addition of simethicone to polyethylene glycol-electrolyte solution: a randomized single-blind study. Clin Transl Gastroen. 2012;3:e26. doi:10.1038/ctg.2012.16
7. Keeratichananont S, Sobhonslidsuk A, Achalanan N, Kitiyakara T, Soonthornpun S. The role of liquid simethicone in enhancing endoscopic visibility prior to esophagogastroduodenoscopy: a prospective randomized, double-blinded, lacebo-controlled trial. Gastrointest Endosc. 2009;69:223-231. doi:10.1016/j.gie.2009.03.531

8. Chen HW, Hsu HC, Hsieh TY, Yeh MK, Chang WK. Pre-medication to improve Esophagogastroduodenoscopic visibility: a meta-analysis and systemic review. Hepatogastroenterology. 2014;61:1642-1648.

9. Hirschowitz BI, Bolt RJ, Pollard HM. Defoaming in gastroscopy with silicone. Gastroenterology. 1954;27:649-651. doi:10.1016/S00165085(19)36107-4

10. Liu XL, Han Y, Wu GX. Dimethicone powder applied under endoscopy in examination of upper gastrointestinal tract. Chin J Endosc. 2016;22(6):44-46.

11. Wu YH, Feng X, Peng GY, Li YH. The role of dimethicone powders in upper gastrointestinal tract endoscopy examination. Chin J Dig Endosc. 2009;26(2):95-96.

12. Zhang ZJ, Xu MF, Zhan LL, et al. The value of dimethicone powders in the upper gastrointestinal tract under endoscopy. Chin $J$ Gastroenterol Hepatol. 2013;22(7):648-652.

13. Lin SF, Bo CX, Zou TR, Wu JY. Comparative observation of defoaming effect of dimethicone powders. Sichuan Medical J. 1985;6(6):350-351.

14. Moore DE, Liu TX, Miao WG, Edwards A, Elliss RARP. LC method with evaporative light scattering detection for the assay of simethicone in pharmaceutical formulations. $J$ Pharm Biomed Anal. 2002;30:273-278. doi:10.1016/S0731-7085(02)00321-7

15. Song MJ, Kwek ABE, Law NM, et al. Efficacy of small-volume simethicone given at least $30 \mathrm{~min}$ before gastroscopy. World $J$ Gastrointest Pharmacol Ther. 2016;7(4):572-578. doi:10.4292/ wjgpt.v7.i4.572

16. Singh Y, Meher JG, Raval K, et al. Nanoemulsion: concepts, development and applications in drug delivery. J Control Release. 2017;252:28-49. doi:10.1016/j.jconrel.2017.03.008

17. Gupta A, Eral HB, Hatton TA, Doyle PS. Nanoemulsions: formation, properties and applications. Soft Matter. 2016;12(11):2826-2841. doi:10.1039/C5SM02958A

18. Rai VK, Mishra N, Yadav KS, Yadav NP. Nanoemulsion as pharmaceutical carrier for dermal and transdermal drugdelivery: formulation development, stability issues, basic considerationsandapplications. J Control Release. 2018;270:203-225. doi:10.1016/j.jconrel.2017.11.049

19. Somasundaran P, Mehta SC, Purohit P. Silicone emulsions. Adv Colloid Interface Sci. 2006;128-130:103-109. doi:10.1016/j.cis.2006.11.023

20. Nazir H, Zhang W, Liu Y, et al. Silicone oil emulsions: strategies to improve their stability and applications in hair care products. Int $J$ Cosmetic Sci. 2014;36:124-133. doi:10.1111/ics.12104

21. Nazir H, Lv P, Wang LY, Lian GP, Zhu SP, Ma GH. Uniform-sized silicone oil microemulsions: preparation, investigation of stability and deposition on hair surface. J Colloid Interf Sci. 2011;364 (1):56-64. doi:10.1016/j.jcis.2011.07.096

22. Hayakawa K, Kawaguchi M, Kato T. Protective colloidal effects of hydroxypropyl methyl cellulose on the stability of silicone oil emulsions. Langmuir. 1997;13(23):6069-6073. doi:10.1021/la970306s

23. Yonekura K, Hayakawa K, Kawaguchi M, Kato T. Preparation of stable silicone oil emulsions in the presence of hydroxypropyl methyl cellulose. Langmuir. 1998;14(12):3145-3148. doi:10.1021/la9714014

24. Binks BP, Whitby CP. Silica particle-stabilized emulsions of silicone oil and water: aspects of emulsification. Langmuir. 2004;20:11301137. doi:10.1021/la0303557

25. $\mathrm{Hu} \mathrm{ZH}$, Liao ML, Chen YH, et al. A novel preparation method for silicone oil nanoemulsions and its application for coating hair with silicone. Int J Nanomed. 2012;7:5719-5724.

26. Zhu LF, Li M, Dong JX, Jin YG. Dimethyl silicone dry nanoemulsion inhalations: formulation study and anti-acute lung injury effect. Int $J$ Pharm. 2015;491:292-298. doi:10.1016/j. ijpharm.2015.06.041 
27. Lei SG, Tian CC, Luo YH, Chen Q, Chen J. Comparative study on the defoaming properties of simethicone and dimethicone. Chin J Pharm Anal. 2012;32(2):296-300.

28. Choudhury S, Dasgupta S, Patel DK, Ramani YR, Ghosh SK, Mazumder B. Nanoemulsion as a carrier for topical delivery of aceclofenac. Giri PK, Goswami DK, Perumal A, editors. Advanced Nanomaterials and Nanotechnology. Springer Proceedings in Physics,143, doi:10.1007/978-3-642-34216-5_1, Springer-Verlag Berlin Heidelberg 2013, 1-19.

29. Yao KF, Clements DJM, Xiang JX, et al. Improvement of carotenoid bioaccessibility from spinach by co-ingesting with excipient nanoemulsions: impact of the oil phase composition. Food Funct. 2019;10:5302-5311. doi:10.1039/C9FO01328H

30. Chaiyana W, Saeio K, Hennink WE, Okonog S. Characterization of potent anticholinesterase plant oil based microemulsion. Int J Pharm. 2010;401:32-40. doi:10.1016/j.ijpharm.2010.09.005

31. Yao B, Yang L. Equilibrium partition of polycyclic aromatic hydrocarbons in cloud point extraction with a silicone surfactant. J Colloid Interface Sci. 2008;319(1):316-321. doi:10.1016/j.jcis.20 07.11 .033

32. Boyd J, Parkinson C, Sherman P. Factors affecting emulsion stability, and the HLB concept. J Colloid Interface Sci. 1972;41(2):359-370. doi:10.1016/0021-9797(72)90122-1

33. Yadav NP, Meher JG, Pandey N, Luqman S, Yadav KS, Chanda D. Enrichment, development, and assessment of Indian basil oil based antiseptic cream formulation utilizing hydrophilic-lipophilic balance approach. Bio Med Res Int. 2013;2013:9. doi:10.1155/2013/410686)

34. Meher JG, Yadav NP, Sahu JJ, Sinha P. Determination of required hydrophilic-lipophilic balance of citronella oil and development of stable cream formulation. Drug Dev Ind Pharm. 2013;39(10):15401546. doi:10.3109/03639045.2012.719902

35. Ross S, Young GJ. Action of antifoaming agents at optimum concentrations. Indus Eng Chem. 1951;43(11):2520-2525. doi:10.1021/ ie50503a036

36. Partenhauser A, Netsomboon K, Leonaviciute G, Bernkop-Schnurch A. Evaluation of thiolated silicone oil as advanced mucoadhesive antifoaming agent. Drug Deliv. 2015;Early Online:1-9. doi:10.3109/ 10717544.2015.1054051
37. Birtley RDN, Burton JS, Kellett DN, Oswald BJ, Pennington JC. The effect of free silica on the mucosal protective and antiflatulent properties of polydimethylsiloxane. J Pharm Pharmaco. 1973;25(11):859863. doi:10.1111/j.2042-7158.1973.tb09963.x

38. Wooster TJ, Golding M, Sanguansri P. Impact of oil type on nanoemulsion formation and ostwald ripening stability. Langmuir. 2008;24 (22):12758-12765. doi:10.1021/1a801685v

39. Abdelmonem R, Younis MK, Hassan DH, et al. Formulation and characterization of chlorhexidine $\mathrm{HCl}$ nanoemulsion as a promising antibacterial root canal irrigant: in-vitro and ex-vivo studies. Int $J$ Nanomed. 2019;14:4697-4708. doi:10.2147/IJN.S204550

40. Oyafuso MH, Carvalho FC, Chiavacci LA, Gremiao MPD, Chorilli M. Design and characterization of silica and surfactant based systems for topical drug delivery. J Nanosci Nanotechnolo. 2015;15:817-826. doi:10.1166/jnn.2015.9181

41. Parekh VJ, Desai ND, Shaikh MS, Shinde UA. Self nanoemulsifying granules (SNEGs) of meloxicam: preparation, characterization, molecular modeling and evaluation of in vivo anti-inflammatory activity. Drug Dev Ind Pharm. 2017;43(4):600-610. doi:10.1080/036390 45.2016.1275665

42. Hussain A, Altamimi MA, Alshehri S, Imam SS, Shakeel F, Singh SK. Novel approach for transdermal delivery of rifampicin to induce synergistic antimycobacterial effects against cutaneous and systemic tuberculosis using a cationic nanoemulsion gel. Int $J$ Nanomed. 2020;15:1073-1094. doi:10.2147/IJN.S236277

43. Pavoni L, Perinelli DR, Bonacucina G, Cespi M, Palmieri GF. An overview of micro- and nanoemulsions as vehicles for essential oils: formulation, preparation and stability. Nanomaterials. 2020;10(13 5):1-24. doi:10.3390/nano10010135

44. Karami Z, Zanjani MRS, Hamidi M. Nanoemulsions in CNS drug delivery: recent developments, impacts and challenges. Drug Discov Today. 2019;24(5):1104-1115. doi:10.1016/j.drudis.2019.03.021(1-34)

45. Hussaina A, Shakeelb F, Singha SK, et al. Solidified SNEDDS for the oral delivery of rifampicin: evaluation, proof of concept, in vivo kinetics, and in silico GastroPlus ${ }^{\mathrm{TM}}$ simulation. Int $J$ Pharm. 2019;566:203-217. doi:10.1016/j.ijpharm.2019.05.061
International Journal of Nanomedicine

\section{Publish your work in this journal}

The International Journal of Nanomedicine is an international, peerreviewed journal focusing on the application of nanotechnology in diagnostics, therapeutics, and drug delivery systems throughout the biomedical field. This journal is indexed on PubMed Central, MedLine, CAS, SciSearch ${ }^{\mathbb{}}$, Current Contents ${ }^{\mathbb{R}} /$ Clinical Medicine,
Journal Citation Reports/Science Edition, EMBase, Scopus and the Elsevier Bibliographic databases. The manuscript management system is completely online and includes a very quick and fair peer-review system, which is all easy to use. Visit http://www.dovepress.com/ testimonials.php to read real quotes from published authors. 